\title{
Does the location of perfusion defects matter?
}

\section{An old question with a new answer}

\author{
Mouaz H. Al-Mallah, MD, MSc, ${ }^{\text {a,b,c }}$ and Waqas Qureshi, MD
}

\section{See related article, pp. 458-464}

Coronary artery disease $(\mathrm{CAD})$ remains the leading cause of death in the USA. Since effective management of this disease is available, it is crucial to properly risk stratify these patients and to provide aggressive treatment to the high-risk patients.

Epidemiologic data have previously shown that the majority of the ST elevation myocardial infarctions (STEMIs) occur in the territories of left anterior descending (LAD) artery followed by the right coronary artery (RCA). ${ }^{1,2}$ In many studies, the site of infarction was an important predictor of outcomes. More specifically, the proximal LAD territory was found to be associated with the highest risk and thus its involvement in $\mathrm{CAD}$ was incorporated into various prognostic risk models. ${ }^{3-5}$ Whether this worse prognosis is due to the larger size of the infarct or the location of the infarct is still debatable. However, some data of the pre-revascularization era showed that there is an independent contribution of location of infarct, independent of the size of the infarction. ${ }^{3,6}$ This association ranged from marginal $^{7}$ to overt ${ }^{8,9}$ in subgroup analysis of randomized controlled trials and observation studies. In the revascularization era, the association of worse clinical outcomes with LAD infarcts continued to be observed.

Proximal LAD infarcts are also associated with worse, not only short-term but also long term, outcomes. It was initially thought that because the degree of

From Henry Ford Hospital, ${ }^{a}$ Wayne State University, ${ }^{\mathrm{b}}$ Detroit, MI; and King Abdul-Aziz Cardiac Center, ${ }^{\mathrm{c}}$ National Guard Health Affairs, Riyadh, Kingdom of Saudi Arabia.

Reprint requests: Mouaz H. Al-Mallah, MD, MSc, King Abdul-Aziz Cardiac Center, National Guard Health Affairs, Department Mail Code: 1413, P.O. Box 22490, Riyadh 11426, Kingdom of Saudi Arabia; mouaz74@gmail.com.

J Nucl Cardiol 2012;19:412-4.

$1071-3581 / \$ 34.00$

Copyright (c) 2012 American Society of Nuclear Cardiology.

doi:10.1007/s12350-012-9529-6 myocardial necrosis is greater in patients with LAD artery involvement, they would eventually have worse outcomes. Conversely, more recently, it was demonstrated that it is not the amount of myocardial necrosis that leads to worse outcomes, but it is the degree of remodeling and resulting left ventricular dysfunction associated with these large infarcts, which predicts the worse long-term outcomes. ${ }^{10-13}$

Single photon emission computed tomography (SPECT) is a functional imaging study that provides a visual demonstration of regional perfusion of myocardium. The utility of SPECT in risk stratification for CAD has been well established. ${ }^{14}$ SPECT imaging has good overall accuracy to differentiate perfusion defects due to stenosis in different vascular territories. However, the prognostic value of different perfusion defects locations was not evaluated before.

\section{DOES LOCATION OF PERFUSION DEFECT ON SPECT MPI PREDICT OUTCOMES?}

In this issue of the Journal, Slim et $\mathrm{al}^{15}$ evaluated the prognostic importance of location of perfusion defects in a cohort of 4,937 patients who underwent exercise and pharmacological SPECT. In the 4,937 patients with single-vessel perfusion defects, 1,774 (35.9\%) had LAD defects, 2,864 (58\%) had RCA territory defects, and 299 (6.1\%) LCx territory defects, while in the two-vessel perfusion defect group of 2,907 patients, 1,232 (52.4\%) had LAD involvement with another vessel territory. Those authors showed that the cardiac deaths and non-fatal myocardial infarction (MI) did not differ in patients with LAD defect compared with non-LAD defect.

On a first glance, these data appear contradictory to prior coronary angiography and acute MI registry data. The coronary angiography data from the Duke database have shown that the revascularizing left main and the proximal LAD arteries are associated with a significant mortality benefit, while revascularizing other lesions might not impact mortality. ${ }^{16}$ A similar relation was shown in the coronary computed tomography angiography (CCTA) literature, where the proximal LAD lesions were associated with worse outcomes, compared with the lesions in other vessels. ${ }^{17}$ 
The discrepancy that we see here can be explained as follows:

1. SPECT myocardial perfusion imaging is a physiological study that provides functional and prognostic assessment of hemodynamically significant stenosis as compared to coronary angiography and CCTA, which only provide limited functional and prognostic data, and it may miss hemodynamically non-significant lesions. Nearly two-thirds of the vulnerable plaques that lead to MI were found to be non-flow limiting and hemodynamically insignificant in previous studies.

2. In patients with known CAD (who were not excluded from this analysis), the defect localization might not be as accurate due to the presence of collateral circulation, micro-vascular obstruction, left bundle branch block or bypass grafts, etc. Thus, the localization of defects in these patients and correlating with anatomical sites may not be as accurate compared with patients without known CAD. Moreover, in patients with diffuse multi-vessel disease, the extent of disease can be underestimated by $30-50 \%{ }^{18}$ Thus, underestimation of LAD disease may happen, especially if higher degree of ischemia is present in other vascular territories.

\section{DOES LOCATION OF CORONARY ARTERY PREDICT SITE OF MI?}

Another logical question arises: Are perfusion defects observed on SPECT associated with cardiac events in the same territory where they were observed? In two small studies, researchers found that the site of perfusion defect did not correlate with the site of subsequent MIs. Later on, larger studies found similar results. ${ }^{19-22}$ This could be because a high degree stenosis might lead to a better collateral circulation, and hence better survival. ${ }^{23}$ The agreement was found to be in the range of 22-64\% in these studies. Based on the autopsy data, Kanei et al. ${ }^{24}$ found that although the scintigraphic defects did not correlate with the site of future AMI, they predicted increased risk of future STEMI. This implies that a higher atherosclerotic plaque burden acts as a surrogate marker of future cardiac events.

Another important finding in this study is that the degree of stress-induced perfusion abnormalities is more important than the location of the perfusion defect. The prognostic value of perfusion abnormalities has been well documented before. ${ }^{25}$ This analysis emphasized this further and clearly showed that the severity of perfusion defect is more important than the location of defect. Thus, the lack of outcome difference between the different groups in this study is most likely due to the absence of significant differences in ischemia burden. Some could argue that patients with proximal LAD lesions may be associated with a higher ischemic burden than those with an RCA or LCx lesion which in turn may result in worse long-term outcome. However, this specific case scenario was not evaluated in this analysis, and further research is needed.

\section{CONCLUSION}

In conclusion, in a clinical setting, it is important to also adopt a holistic approach in determining the risk of future cardiovascular mortality, while taking into account risk factors for CAD, patient-based characteristics and high risk predictors on MPI and just not rely on the location of the coronary artery involvement on a myocardial perfusion imaging. It should be also kept in mind that even though the agreement between morphological and functional studies is not great, the complimentary information provided by both the studies has an incremental value in the management of CAD patients.

\section{References}

1. Wang JC, Normand SL, Mauri L, Kuntz RE. Coronary artery spatial distribution of acute myocardial infarction occlusions. Circulation 2004;110:278-84.

2. Schmitt C, Lehmann G, Schmieder S, Karch M, Neumann FJ, Schomig A. Diagnosis of acute myocardial infarction in angiographically documented occluded infarct vessel: Limitations of ST-segment elevation in standard and extended ECG leads. Chest 2001;120:1540-6

3. Bourke S, Conroy RM, Mulcahy R, Robinson K. Aetiological and prognostic correlates of site of myocardial infarction. Eur Heart $\mathbf{J}$ 1988;9:734-9.

4. Lee KL, Woodlief LH, Topol EJ, et al. Predictors of 30-day mortality in the era of reperfusion for acute myocardial infarction. Results from an international trial of 41,021 patients. GUSTO-I Investigators. Circulation 1995;91:1659-68.

5. Morrow DA, Antman EM, Charlesworth A, et al. TIMI risk score for ST-elevation myocardial infarction: A convenient, bedside, clinical score for risk assessment at presentation: An intravenous nPA for treatment of infarcting myocardium early II trial substudy. Circulation 2000;102:2031-7.

6. Hands ME, Lloyd BL, Robinson JS, de Klerk N, Thompson PL. Prognostic significance of electrocardiographic site of infarction after correction for enzymatic size of infarction. Circulation 1986;73:885-91.

7. Benhorin J, Moss AJ, Oakes D, et al. The prognostic significance of first myocardial infarction type ( $Q$ wave versus non-Q wave) and Q wave location. The Multicenter Diltiazem Post-Infarction Research Group. J Am Coll Cardiol 1990;15:1201-7.

8. Kornowski R, Goldbourt U, Reicher-Reiss H, et al. Prognostic significance of infarction location in patients with recurrent myocardial infarction. SPRINT Study Group. Secondary Prevention Reinfarction Israel Nifedipine Trial. Cardiology 1997;88:441-5.

9. Molstad P. Prognostic significance of type and location of a first myocardial infarction. J Intern Med 1993;233:393-9. 
10. Masci PG, Ganame J, Francone M, et al. Relationship between location and size of myocardial infarction and their reciprocal influences on post-infarction left ventricular remodelling. Eur Heart J 2011;32:1640-8

11. Elsman P, van 't Hof AW, de Boer MJ, et al. Impact of infarct location on left ventricular ejection fraction after correction for enzymatic infarct size in acute myocardial infarction treated with primary coronary intervention. Am Heart J 2006;151:1239.e9-14

12. Cacciapuoti F, Arciello A, Fiandra M, Manfredi E, Lama D. Index of myocardial performance after early phase of myocardial infarction in relation to its location. J Am Soc Echocardiogr 2004;17:345-9.

13. Nienhuis MB, Ottervanger JP, Dambrink JH, et al. Comparative predictive value of infarct location, peak $\mathrm{CK}$, and ejection fraction after primary PCI for ST elevation myocardial infarction. Coron Artery Dis 2009;20:9-14.

14. Berman DS, Hachamovitch R, Kiat $\mathrm{H}$, et al. Incremental value of prognostic testing in patients with known or suspected ischemic heart disease: a basis for optimal utilization of exercise technetium-99m sestamibi myocardial perfusion single-photon emission computed tomography. J Am Coll Cardiol 1995;26:639-47.

15. Slim HB, Nair SU, Arora S, Heller G. Does location matter? prognostic value of Single Photon Emission Computed Tomography myocardial perfusion imaging by vascular territory. J Nucl Cardiol 2011 [Epub ahead of print].

16. Jones RH, Kesler K, Phillips HR 3rd, et al. Long-term survival benefits of coronary artery bypass grafting and percutaneous transluminal angioplasty in patients with coronary artery disease. J Thorac Cardiovasc Surg 1996;111:1013-25.

17. Min JK, Shaw LJ, Devereux RB, et al. Prognostic value of multidetector coronary computed tomographic angiography for prediction of all-cause mortality. J Am Coll Cardiol 2007;50: 1161-70.
18. Berman DS, Kang X, Slomka PJ, et al. Underestimation of extent of ischemia by gated SPECT myocardial perfusion imaging in patients with left main coronary artery disease. J Nucl Cardiol 2007; $14: 521-8$.

19. Miller GL, Herman SD, Heller GV, et al. Relation between perfusion defects on stress technetium-99m sestamibi SPECT scintigraphy and the location of a subsequent acute myocardial infarction. Am J Cardiol 1996;78:26-30.

20. Naqvi TZ, Hachamovitch R, Berman D, Buchbinder N, Kiat H, Shah PK. Does the presence and site of myocardial ischemia on perfusion scintigraphy predict the occurrence and site of future myocardial infarction in patients with stable coronary artery disease? Am J Cardiol 1997;79:1521-4.

21. Candell-Riera J, Pereztol-Valdes O, Santana-Boado C, et al. Relationship between the location of the most severe myocardial perfusion defects, the most severe coronary artery stenosis, and the site of subsequent myocardial infarction. J Nucl Med 2001;42: 558-63.

22. Galvin JM, Brown KA. The site of acute myocardial infarction is related to the coronary territory of transient defects on prior myocardial perfusion imaging. J Nucl Cardiol 1996;3:382-8.

23. Meier P, Hemingway H, Lansky AJ, Knapp G, Pitt B, Seiler C. The impact of the coronary collateral circulation on mortality: A meta-analysis. Eur Heart J 2011 [Epub ahead of print].

24. Kanei Y, Huang Y, Fox JT, Rachko M, Bergmann SR. Correlation of antecedent stress myocardial perfusion imaging with the infarct related artery in ST-elevation myocardial infarction. Int J Cardiovasc Imaging 2009;25:145-9.

25. Hachamovitch R, Berman DS, Shaw LJ, et al. Incremental prognostic value of myocardial perfusion single photon emission computed tomography for the prediction of cardiac death: differential stratification for risk of cardiac death and myocardial infarction. Circulation 1998;97:535-43. 